\title{
Role of combined immunomodulator therapy in severe steroid intolerant vernal keratoconjunctivitis
}

\author{
Prafulla Kumar Maharana $^{1} \cdot$ Deepali Singhal $^{1} \cdot$ Nimmy $^{\text {Raj }}{ }^{1} \cdot$ Namrata Sharma $^{1} \cdot$ Jeewan S. Titiyal $\mathbb{D}^{1}$
}

Received: 23 February 2020 / Revised: 16 May 2020 / Accepted: 28 May 2020 / Published online: 9 June 2020

(c) The Author(s), under exclusive licence to The Royal College of Ophthalmologists 2020

\begin{abstract}
Purpose To describe the role of combined topical cyclosporine (CsA) $0.1 \%$ and tacrolimus $0.03 \%$ in cases with severe steroid intolerant vernal keratoconjunctivitis (VKC).

Methods Medical records of patients with acute exacerbation of VKC and steroid intolerance referred from glaucoma to cornea clinic were reviewed from March 2017 to December 2018. Eleven patients (22 eyes), (nine with steroid-induced glaucoma, two with steroid-induced cataract and glaucoma) were found. All were started on topical CsA 0.1\% QID. Due to suboptimal response at 2 weeks, topical tacrolimus $0.03 \%$ BD was also included.

Results The mean total subjective score at presentation was $13 \pm 1.4$, which reduced to $11.2 \pm 1.3$ at 2 weeks of topical CsA therapy and further reduced to $5 \pm 0$ at 2 weeks of combination therapy $(p<0.001)$. The mean total objective score at presentation was $9.4 \pm 1.4$ that reduced to $8.0 \pm 1.3$ at 2 weeks of topical CsA therapy and further reduced to $4.3 \pm 1.6$ at 2 weeks of combination therapy $(p<0.001)$. Similar results were obtained in a sub-group analysis including the worse eye or right eye of the cases only. The absolute change in the total subjective and objective score was much more with combination therapy. Photophobia and conjunctival hyperemia resolved within 4 weeks of combined therapy. No recurrence was observed till 6 months follow-up.

Conclusions Combined use of cyclosporine and tacrolimus may lead to rapid resolution of symptoms and reduced recurrence rate in cases with severe VKC where steroid has to be avoided.
\end{abstract}

\section{Introduction}

Vernal keratoconjunctivitis (VKC) is a chronic, bilateral, and seasonal allergic inflammatory disease of the eye primarily involving the tarsal and bulbar conjunctiva. It is characterized by episodes of acute exacerbations marked by ropy discharge, itching, conjunctival congestion, and corneal involvement in severe cases [1]. Topical steroids are the treatment of choice for acute symptomatic cases of VKC. However, long-term use of steroids can lead to complications like glaucoma and cataract. In addition, patients who are steroid responder can develop acute rise in intraocular pressure (IOP) following steroid use. Control of

Prafulla Kumar Maharana

drpraful13@gmail.com

1 Department of Ophthalmology, Dr. Rajendra Prasad Centre for Ophthalmic Sciences, All India Institute of Medical Sciences, New Delhi, India inflammation in such cases is often difficult. The difficulty is largely due to the unavailability of topical antiinflammatory drugs as potent as topical steroids [2]. Ang et al. reported an incidence of $28.3 \%$ of steroid-induced raised IOP in patients with VKC $(n=145)$ of which 5.5\% developed glaucoma [3]. Similarly in another study, the same group of authors reported the need for trabeculectomy with mitomycin $\mathrm{C}$ in $16.6 \%$ cases with steroid-induced glaucoma in VKC [4].

Recently, several reports have demonstrated the efficacy of topical formulations of cyclosporine (CsA) and tacrolimus in cases of acute VKC [5-11]. Th2 lymphocyte activation plays a role in pathogenesis of VKC. CsA, an immunomodulator that acts by blocking Th2 lymphocyte proliferation and IL-2 production, has a role in management of VKC. It has other actions like inhibition of histamine release from mast cells and basophils through reduction in IL-5 production; inhibition of recruitment of eosinophils that further contributes to its effectiveness in VKC [12]. Tacrolimus is similar to CsA in its mode of action. Ocular irritation is the most common side effect reported [11, 13]. 
Low-dose topical formulations such as 0.01 and $0.005 \%$ tacrolimus eye drops, four times a day, have also been described for refractory cases of VKC $[14,15]$.

Both CsA and tacrolimus have been used as a primary therapy in acute exacerbation of VKC in cases with steroid intolerance or resistance [5, 6, 16-21]. It is well known that tacrolimus is more potent than CsA [22]. Besides, they bind to different categories of immunophilins and tacrolimus might also be acting through other pathways of inhibiting inflammation than calcineurin receptor blockade alone, we believe that a combination of these two drugs will have a synergistic effect leading to a rapid resolution of inflammation [22]. In fact, the clinical efficacy of combined use of CsA and tacrolimus has already been reported by Tzu et al. in cases of atopic keratoconjunctivitis (AKC) and lid eczema [23].

Herein, we report cases of steroid intolerant VKC in whom an initial attempt was made to control the disease using CsA only but the response to treatment was below expectation. In all these cases, the disease could be controlled after inclusion of tacrolimus in the treatment regimen.

\section{Methods}

This study was a retrospective case series. All patients who were referred from glaucoma clinic to the cornea clinic for management of acute exacerbation of VKC and were either steroid responder or had steroid-induced glaucoma or cataract due to which they could not be started on steroids were included in the study. Medical records of all such patients were reviewed from the Cornea clinic of Dr. Rajendra Prasad Centre for Ophthalmic Sciences, a tertiary eye care hospital, from March 2017 to December 2018. The research was conducted adhering to the tenets of the Declaration of Helsinki. Twenty-two eyes of eleven patients of VKC in whom steroids had to be avoided were included. Out of these 22 eyes, 18 eyes of 9 cases had steroid-induced glaucoma while 4 eyes of 2 cases had steroid-induced cataract and glaucoma both.

The details regarding the history, including age of onset, age, duration of disease, sex, frequency of episodes per year, steroid use frequency per year, occupation, symptoms, history of any atopic disorder, previous history of any intervention like supratarsal steroid injections, or recent surgery like trabeculectomy were recorded. Best spectaclecorrected visual acuity was recorded using both Snellen and logarithm of minimum angle of resolution ( $\log M A R)$ scales.

The size of the papillae and any congestion at the base were recorded by inversion of the eyelids. All examination findings including external eye, slit-lamp, and posterior segment were recorded.

We excluded patients who were already using topical CsA or tacrolimus, and who had ever used a systemic immunosuppressant. Symptoms and signs were recorded and scored following the published report by Muller et al. before the introduction of therapy and after 2 weeks of CsA, 2 weeks of adding tacrolimus, 1 month, 3 months, and 6 months of follow-up (Table 1 and Fig. 1) [24].

All cases were started on topical olopatadine hydrochloride $0.2 \%$ (Pataday, Alcon) once daily and topical carboxymethyl cellulose $0.1 \%$ (Refresh liquigel, Alcon) six times a day from the glaucoma clinic. Topical CsA $0.1 \%$ (Nanotears, Sunways (India) Pvt Ltd) four times a day was started from the cornea clinic and all antiglaucoma medications were continued as required. Due to suboptimal response at 2 weeks, topical tacrolimus $0.03 \%$ ointment $\mathrm{BD}$ (Talimus, Ajanta pharmaceuticals, India) was included in the treatment regimen which was continued for 1 month and then tapered to OD dose for 1 month and subsequently reduced to OD alternate day therapy for 1 month. The ointment was applied in the inferior fornix. Thus, tacrolimus was continued for 3 months following which, the patients were maintained on CsA only.

\section{Statistical analysis}

Statistical analysis was performed using Microsoft Excel (Microsoft Office Professional Plus 2013; WA) and Stata statistical software (version 13; StataCorp, TX). Quantitative data was expressed as mean \pm standard deviation. Categorical data was expressed as frequency. Median (Interquartile range) was used to express skewed data. Wilcoxon signed-rank test and paired $t$ tests were used for analysis. A $p$ value of $<0.05$ was considered as statistically significant.

\section{Results}

Twenty-two eyes of 11 patients of VKC in whom steroid eye drops had to be avoided were included in the study. Male:female ratio was 10:1. The mean age at presentation was $13.7 \pm 7.4$ years (median 11 years), ranging from 5 to 28 years. The mean age of onset of VKC was $54.8 \pm$ 39.5 months (median 48 months), ranging from 3 to 156 months. The mean frequency of acute episodes was $3.5 \pm 1.3$ episodes per year. The mean frequency of steroid use was $3.6 \pm 2.4$ episodes per year. One out of eleven patients had associated skin atopic disorder (eczema). The mean IOP was $22 \pm 17.5 \mathrm{mmHg}$ as measured on applanation tonometry. The mean BCVA at presentation was $0.55 \pm 0.6$ $\log$ MAR units. Presence of giant papillae could be 
Table 1 Severity grading of symptoms and signs followed in the study.

\begin{tabular}{|c|c|c|}
\hline Clinical feature & Score & Interpretation \\
\hline \multicolumn{3}{|l|}{ Symptoms } \\
\hline \multirow[t]{4}{*}{ Itching } & 0 & No desire to scratch \\
\hline & $1+$ & Occasional desire to scratch \\
\hline & $2+$ & Frequent desire to scratch \\
\hline & $3+$ & Continuous desire to scratch \\
\hline \multirow[t]{4}{*}{ Tearing } & 0 & Normal Production of tears \\
\hline & $1+$ & Occasional tearing \\
\hline & $2+$ & Intermittent tearing \\
\hline & $3+$ & Constant tearing \\
\hline \multirow[t]{4}{*}{ Foreign body sensation } & 0 & Absent \\
\hline & $1+$ & $\begin{array}{l}\text { Discrete, occasional foreign body } \\
\text { sensation }\end{array}$ \\
\hline & $2+$ & $\begin{array}{l}\text { Mild, frequent foreign body } \\
\text { sensation }\end{array}$ \\
\hline & $3+$ & $\begin{array}{l}\text { Severe, continuous foreign body } \\
\text { sensation }\end{array}$ \\
\hline \multirow[t]{4}{*}{ Photophobia } & 0 & No photophobia \\
\hline & $1+$ & Mild, squints in bright light \\
\hline & $2+$ & Moderate, needs sunglasses \\
\hline & $3+$ & $\begin{array}{l}\text { Severe, cannot withstand bright light } \\
\text { even when wearing sunglasses }\end{array}$ \\
\hline \multirow[t]{4}{*}{ Discharge } & 0 & No discharge \\
\hline & $1+$ & Little, in the fornix \\
\hline & $2+$ & $\begin{array}{l}\text { Moderate, in the fornix, with } \\
\text { crusting on eyelashes }\end{array}$ \\
\hline & $3+$ & $\begin{array}{l}\text { Abundant, wakes up with eyes stuck } \\
\text { shut or washes them several } \\
\text { times a day }\end{array}$ \\
\hline \multicolumn{3}{|l|}{ Signs } \\
\hline \multirow[t]{4}{*}{ Conjunctival hyperemia } & 0 & Absent \\
\hline & $1+$ & Dilation of some blood vessels \\
\hline & $2+$ & Dilation of several blood vessels \\
\hline & $3+$ & $\begin{array}{l}\text { Generalized dilation of blood } \\
\text { vessels }\end{array}$ \\
\hline \multirow[t]{4}{*}{ Tarsal papillary reaction } & 0 & No papillae \\
\hline & $1+$ & $\begin{array}{l}\text { Papillary reaction without giant } \\
\text { papillae }\end{array}$ \\
\hline & $2+$ & Some giant papillae \\
\hline & $3+$ & $\begin{array}{l}\text { Giant papillae all over the tarsal } \\
\text { conjunctiva }\end{array}$ \\
\hline \multirow[t]{4}{*}{ Limbal neovascularization } & 0 & No neovessels \\
\hline & $1+$ & Neovessels in 1 quadrant \\
\hline & $2+$ & Neovessels in 2 quadrants \\
\hline & $3+$ & Neovessels in 3 or 4 quadrants \\
\hline \multirow[t]{4}{*}{ Conjunctival fibrosis } & 0 & No scars \\
\hline & $1+$ & Subepithelial fibrosis \\
\hline & $2+$ & Fornix shortening \\
\hline & $3+$ & Symblepharon \\
\hline \multirow[t]{4}{*}{ Punctate keratopathy } & 0 & Intact epithelium \\
\hline & $1+$ & Punctate in $1 / 3$ of the cornea \\
\hline & $2+$ & Punctate in $2 / 3$ of the cornea \\
\hline & $3+$ & Diffuse punctate \\
\hline
\end{tabular}

identified in 4/22 eyes (18.1\%) with acquired ptosis in $2 / 22$ eyes $(9 \%)$. On slit-lamp evaluation, Horner-tranta's spots were present in $12 / 22$ eyes (54.5\%), pseudogerontoxon in $7 / 22$ eyes $(31.8 \%)$, and shield ulcer in $4 / 22$ eyes (18.1\%).
Prominent palisades of vogt were identified in $4 / 22$ eyes $(18.1 \%)$. Out of 22 eyes, 20 eyes $(90.9 \%)$ had type 3 (mixed) VKC and 2 eyes (9\%) had type 2 (palpebral) VKC. Steroid-induced cataract was seen in $8 / 22$ eyes $(36.3 \%)$. Keratoconus was observed in $8 / 22(36.3 \%)$ eyes using Amsler-Krumeich grading. The mean tear film break-up time was $5.9 \pm 3.7 \mathrm{~s}$ and mean Schirmer value was $19.9 \pm$ $7.6 \mathrm{~mm}$ at $5 \mathrm{~min}$.

Thirteen out of twenty-two eyes (59\%) showed cupping and thinning of neuro-retinal rim on fundus evaluation. The mean retinal nerve fiber layer (RNFL) thickness was $58.4 \pm$ 17.7, $59.7 \pm 21.2,78.1 \pm 36.8$, and $95.7 \pm 36.7$ microns in nasal, temporal, superior, and inferior quadrant, respectively. The average RNFL thickness was $292 \pm 87.7$ microns. Impression cytology could be possible in thirteen eyes to look for limbal stem cell deficiency and presence of goblet cells could be identified only in one eye. The mean keratometry was measured to be $42.9 \pm 5.3 \mathrm{D} \times 46.8 \pm 6.7 \mathrm{D}$ on corneal topography while the mean kmax was $49.13 \pm$ 6.7 D. The mean thinnest pachymetry was $498.1 \pm 86$ microns and mean posterior elevation was $26.7 \pm 24.5 \mathrm{D}$.

\section{Subjective/symptoms scoring}

The mean total subjective score at baseline was $13 \pm 1.4$, thereafter, at 2 weeks of topical CsA therapy this score significantly reduced to $11.2 \pm 1.3(p=0.001)$. However, the total score further reduced significantly to $5 \pm 0$ at 2 weeks of combination therapy of CsA and tacrolimus ( $p<$ 0.001 ). The absolute change in the total subjective score was much more after the inclusion of topical tacrolimus (Table 2 and Fig. 2a). On further evaluation of the trend of resolution of symptoms, for itching, the number of eyes with score 3 at baseline $(15 / 22,68.1 \%)$ was reduced by $60 \%$ at 2 weeks of topical CsA $(6 / 22,27.2 \%)$. However, all 22 eyes showed reduction of score from $2(16 / 22)$ or 3 (6/22) to score 1 after adding topical tacrolimus to the treatment regimen. Similar trend was observed in all the other symptoms as well (Table 3). Photophobia resolved within 4 weeks of combined treatment.

\section{Objective/signs scoring}

The mean total objective score at baseline was $9.4 \pm 1.4$ thereafter, at 2 weeks of topical CSA therapy this score significantly reduced to $8.0 \pm 1.3(p=0.001)$. However, the total score further reduced significantly to $4.3 \pm 1.6$ at 2 weeks of combination therapy of CSA and tacrolimus $(p<0.001)$. The absolute change in the total objective score was much more after the inclusion of topical tacrolimus (Table 2 and Fig. 2b). On further evaluation of the trend of resolution of signs, for conjunctival hyperemia the number of eyes with score 3 at baseline $(15 / 22,68.1 \%)$ were 

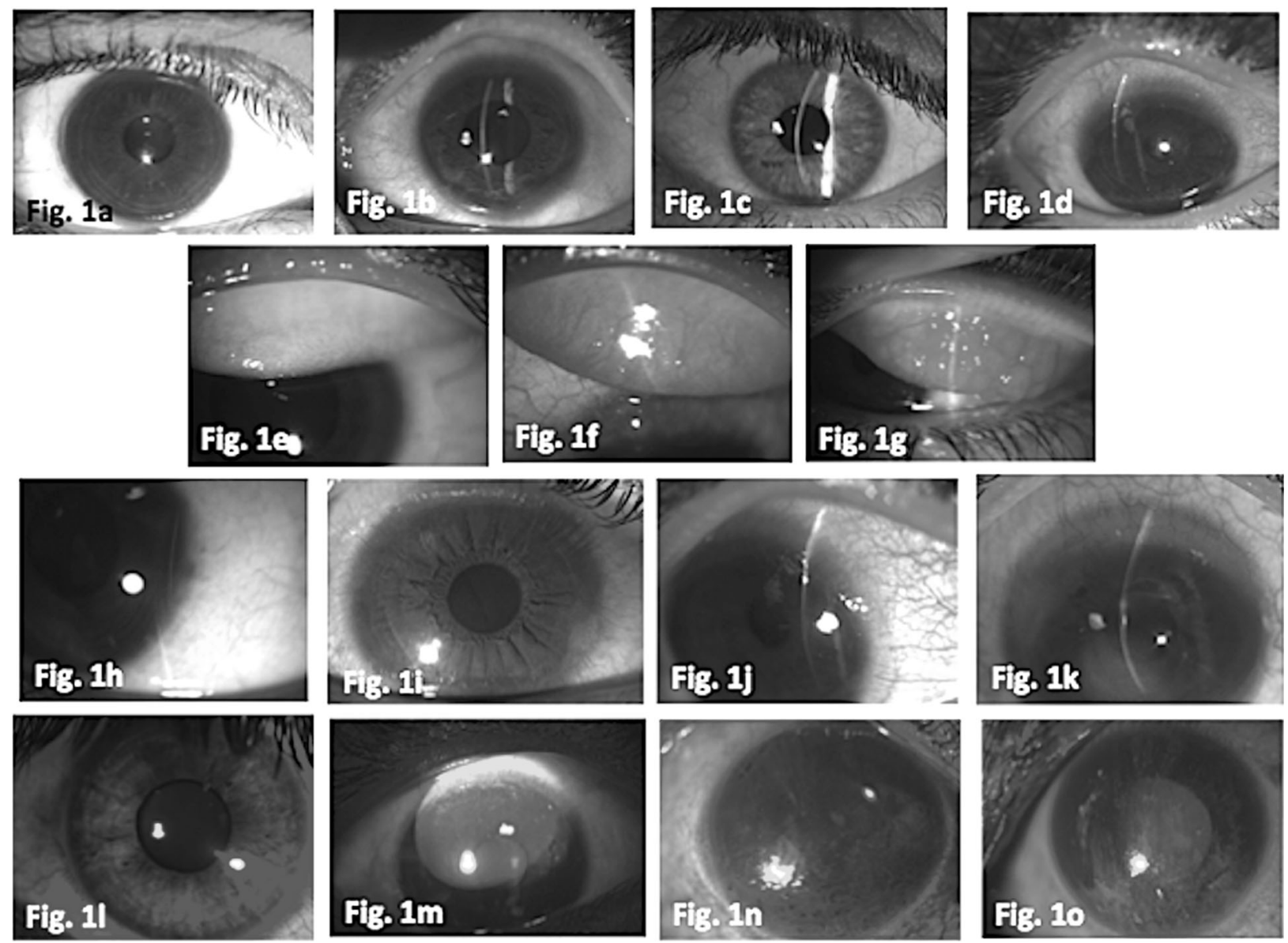

Fig. 1 Clinical photographs showing the clinical scoring of signs in VKC. Scoring of conjunctival hyperemia, a no hyperemia (0), b dilation of some blood vessels $(1+)$, c dilation of several blood vessels $(2+)$, $\mathbf{d}$ generalized dilation of blood vessels $(3+)$. Scoring of tarsal papillary reaction, e no papillae (0), $\mathbf{f}$ papillary reaction without giant papillae $(1+)$, g giant papillae all over tarsal conjunctiva $(3+)$,

similarly when some giant papillae are seen it is score $2+. \mathbf{h}-\mathbf{k}$ Scoring of limbal vascularization, no neovessels $(0)$, neovessels in 1 quadrant $(1+)$, neovessels in two quadrants $(2+)$, neovessels in 3 or 4 quadrants (3+). l-o Scoring of punctate keratopathy, no staining (0), punctate stain in $1 / 3$ rd of cornea $(1+)$, punctate stain in $2 / 3$ rd of cornea $(2+)$, diffuse staining $(3+)$.

Table 2 Change in the total subjective and objective score from baseline to 6 months follow-up.

\begin{tabular}{lllll}
\hline Parameter & $\begin{array}{l}\text { Baseline to } \\
\text { 2-week CsA }\end{array}$ & $\begin{array}{l}\text { 2-week CsA } \\
\text { to 2-week } \\
\text { CsA }+ \\
\text { tacrolimus }\end{array}$ & $\begin{array}{l}\text { 2-week CsA } \\
+ \text { tacrolimus } \\
\text { to 4 weeks }\end{array}$ & $\begin{array}{l}\text { 4-week CsA } \\
+ \text { tacrolimus } \\
\text { to } 6 \text { months }\end{array}$ \\
\hline $\begin{array}{l}\text { Total subjective score change } \\
N \text { (eyes) }\end{array}$ & 22 & 22 & 22 & 22 \\
Mean & 1.8 & 6.2 & 4.3 & 0.6 \\
SD & 1.5 & 1.3 & 1.1 & 1.0 \\
P50 & 1.5 & 6 & 5 & 0 \\
Minimum & 0 & 5 & 2 & 0 \\
Maximum & 5 & 10 & 5 & 3 \\
Total objective & score change & & & 22 \\
$N$ (eyes) & 22 & 22 & 22 & 0.2 \\
Mean & 1.3 & 3.7 & 3.7 & 0.4 \\
SD & 1.0 & 0.9 & 0.4 & 0 \\
P50 & 1 & 3 & 4 & 0 \\
Minimum & 0 & 3 & 3 & 1 \\
Maximum & 3 & 6 & 4 & \\
\hline
\end{tabular}

$N$ number of eyes, CsA topical ciclosporin A $0.05 \%$.

reduced by $60 \%$ at 2 weeks of topical cyclosporin $(6 / 22$, $27.2 \%)$. However, all 22 eyes showed reduction of score from $2(16 / 22)$ or $3(6 / 22)$ to score 1 after adding topical tacrolimus to the treatment regimen. Similar trend was observed in all the other signs as well (Table 4 and Fig. 3). Conjunctival hyperemia resolved within 4 weeks of starting combined therapy while no recurrence was observed till 6 months follow-up.

\section{Sub-group analysis}

A sub-group analysis was done including only the worse eye or right eye in patients with same scoring in both eyes. The mean total subjective score at baseline was $13.5 \pm 1.3$, thereafter, at 2 weeks of topical CsA therapy this score significantly reduced to $11.2 \pm 1.2(p<0.001)$. This further reduced significantly to $5 \pm 0$ at 2 weeks of combination therapy of CsA and tacrolimus $(p<0.0005)$. Similarly, the mean total objective score at baseline was $9.6 \pm 1.2$ thereafter, 

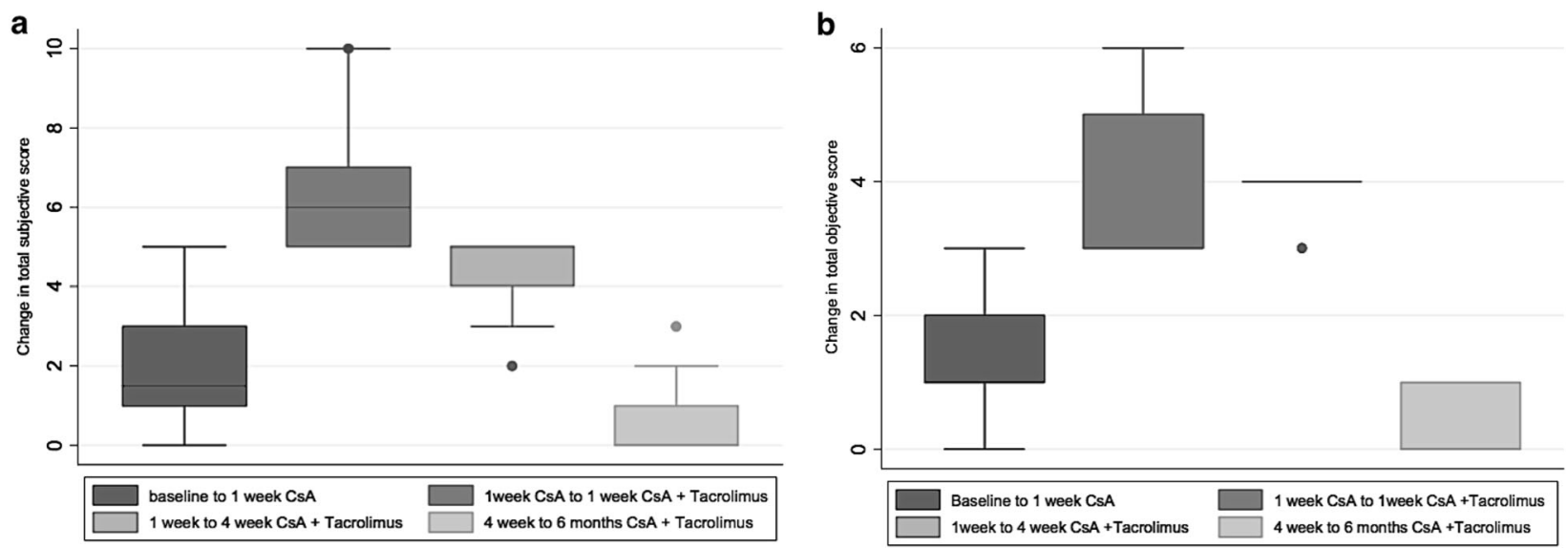

Fig. 2 Change in total score over time. Box plot showing the change in the total subjective (a) and objective (b) score from baseline to 6 months follow-up.

Table 3 Number of eyes having each symptom score from baseline to 6 months follow-up.

\begin{tabular}{|c|c|c|c|c|c|}
\hline Symptom & Duration & $\begin{array}{l}N, \% \text { of eyes with } \\
\text { score } 0\end{array}$ & $\begin{array}{l}N, \% \text { of eyes with } \\
\text { score } 1\end{array}$ & $\begin{array}{l}N, \% \text { of eyes with } \\
\text { score } 2\end{array}$ & $\begin{array}{l}N, \% \text { of eyes with } \\
\text { score } 3\end{array}$ \\
\hline \multirow[t]{5}{*}{ Itching } & Baseline & 0,0 & 0,0 & $7,31.8$ & $15,68.1$ \\
\hline & 2-week CsA & 0,0 & 0,0 & $16,72.7$ & $6,27.2$ \\
\hline & 2-week CsA + T & 0,0 & 22,100 & 0,0 & 0,0 \\
\hline & 4-week CsA + T & 0,0 & 22,100 & 0,0 & 0,0 \\
\hline & 6-month CsA $+\mathrm{T}$ & 22,100 & 0,0 & 0,0 & 0,0 \\
\hline \multirow[t]{5}{*}{ Tearing } & Baseline & 0,0 & 0,0 & $6,27.7$ & $16,72.7$ \\
\hline & 2-week CsA & 0,0 & 0,0 & $18,81.8$ & $4,18.1$ \\
\hline & 2-week CsA + T & 0,0 & 22,100 & 0,0 & 0,0 \\
\hline & 4-week CsA + T & $17,77.2$ & $5,22.7$ & 0,0 & 0,0 \\
\hline & 6-month CsA $+\mathrm{T}$ & 22,100 & 0,0 & 0,0 & 0,0 \\
\hline \multirow[t]{5}{*}{ Foreign body sensation } & Baseline & 0,0 & 0,0 & 11,50 & 11,50 \\
\hline & 2-week CsA & 0,0 & 0,0 & $16,72.7$ & $6,27.7$ \\
\hline & 2-week CsA + T & 0,0 & 22,100 & 0,0 & 0,0 \\
\hline & 4-week CsA + T & $17,77.2$ & $5,22.7$ & 0,0 & 0,0 \\
\hline & 6-month CsA + T & $21,95.4$ & $1,4.5$ & 0,0 & 0,0 \\
\hline \multirow[t]{5}{*}{ Photophobia } & Baseline & 0,0 & 0,0 & 11,50 & 11,50 \\
\hline & 2-week CsA & 0,0 & 0,0 & $16,72.7$ & $6,27.7$ \\
\hline & 2-week CsA $+\mathrm{T}$ & 0,0 & 22,100 & 0,0 & 0,0 \\
\hline & 4-week CsA + T & 22,100 & 0,0 & 0,0 & 0,0 \\
\hline & 6-month CsA $+\mathrm{T}$ & 22,100 & 0,0 & 0,0 & 0,0 \\
\hline \multirow[t]{5}{*}{ Discharge } & Baseline & 0,0 & 0,0 & 11,50 & 11,50 \\
\hline & 2-week CsA & 0,0 & 0,0 & $16,72.7$ & $6,27.7$ \\
\hline & 2-week CsA + T & 0,0 & 22,100 & 0,0 & 0,0 \\
\hline & 4-week CsA + T & $17,77.2$ & $5,22.7$ & 0,0 & 0,0 \\
\hline & 6-month CsA $+\mathrm{T}$ & 21 & 1 & 0 & 0 \\
\hline
\end{tabular}

$N$ number, $C s A$ topical ciclosporin A $0.05 \%, T$ topical tacrolimus $0.03 \%$.

at 2 weeks of topical CSA therapy this score significantly reduced to $7.9 \pm 1.2(p=0.0002)$. However, the total score further reduced significantly to $4.3 \pm 0.6$ at 2 weeks of combination therapy of CSA and tacrolimus $(p<0.0001)$.
One patient developed severe itching following use of tacrolimus and required a short course of low-potency steroid (loteprednol $0.5 \%$ ) for disease control. Disease could be controlled in all except one patient without the use of steroids. 
Table 4 Number of eyes having each sign score from baseline to 6 months follow-up.

\begin{tabular}{|c|c|c|c|c|c|}
\hline Sign & Duration & $\begin{array}{l}N, \% \text { of eyes with } \\
\text { score } 0\end{array}$ & $\begin{array}{l}N, \% \text { of eyes with } \\
\text { score } 1\end{array}$ & $\begin{array}{l}N, \% \text { of eyes with } \\
\text { score } 2\end{array}$ & $\begin{array}{l}N, \% \text { of eyes with } \\
\text { score } 3\end{array}$ \\
\hline \multirow[t]{5}{*}{ Conjunctival hyperemia } & Baseline & 0,0 & 0,0 & $7,31.8$ & $15,68.1$ \\
\hline & 2-week CsA & 0,0 & 0,0 & $16,72.7$ & $6,27.2$ \\
\hline & 2-week CsA $+\mathrm{T}$ & 0,0 & 22,100 & 0,0 & 0,0 \\
\hline & 4-week CsA $+\mathrm{T}$ & 22,100 & 0,0 & 0,0 & 0,0 \\
\hline & 6-month CsA $+\mathrm{T}$ & 22,100 & 0,0 & 0,0 & 0,0 \\
\hline \multirow[t]{5}{*}{ Tarsal papillae } & Baseline & 0,0 & 0,0 & $6,27.7$ & $16,72.7$ \\
\hline & 2-week CsA & 0,0 & 0,0 & $18,81.8$ & $4,18.1$ \\
\hline & 2-week CsA + T & 0,0 & 22,100 & 0,0 & 0,0 \\
\hline & 4-week CsA + T & $17,77.2$ & $5,22.7$ & 0,0 & 0,0 \\
\hline & 6-month CsA $+\mathrm{T}$ & 22,100 & 0,0 & 0,0 & 0,0 \\
\hline \multirow[t]{5}{*}{ Punctate keratopathy } & Baseline & 0,0 & 0,0 & $7,31.8$ & $15,68.1$ \\
\hline & 2-week CsA & 0,0 & 0,0 & $16,72.7$ & $6,27.7$ \\
\hline & 2-week CsA + T & 0,0 & 22,100 & 0,0 & 0,0 \\
\hline & 4-week CsA + T & 22,100 & 0,0 & 0,0 & 0,0 \\
\hline & 6-month CsA $+\mathrm{T}$ & 22,100 & 0,0 & 0,0 & 0,0 \\
\hline \multirow[t]{5}{*}{ Limbal neovascularization } & Baseline & 0,0 & $17,77.2$ & $5,22.7$ & 0,0 \\
\hline & 2-week CsA & 0,0 & $17,77.2$ & $5,22.7$ & 0,0 \\
\hline & 2-week CsA + T & 0,0 & $17,77.2$ & $5,22.7$ & 0,0 \\
\hline & 4-week CsA + T & $17,77.2$ & $5,22.7$ & 0,0 & 0,0 \\
\hline & 6-month CsA $+\mathrm{T}$ & $17,77.2$ & $5,22.7$ & 0,0 & 0,0 \\
\hline \multirow[t]{5}{*}{ Conjunctival fibrosis } & Baseline & $20,90.9$ & $2,9.0$ & 0,0 & 0,0 \\
\hline & 2-week CsA & $20,90.9$ & $2,9.0$ & 0,0 & 0,0 \\
\hline & 2-week CsA $+\mathrm{T}$ & $20,90.9$ & $2,9.0$ & 0,0 & 0,0 \\
\hline & 4-week CsA + T & $20,90.9$ & $2,9.0$ & 0,0 & 0,0 \\
\hline & 6-month CsA $+\mathrm{T}$ & 21 & 1 & 0 & 0 \\
\hline
\end{tabular}

$N$ number, $C s A$ topical ciclosporin A $0.05 \%, T$ topical tacrolimus $0.03 \%$.
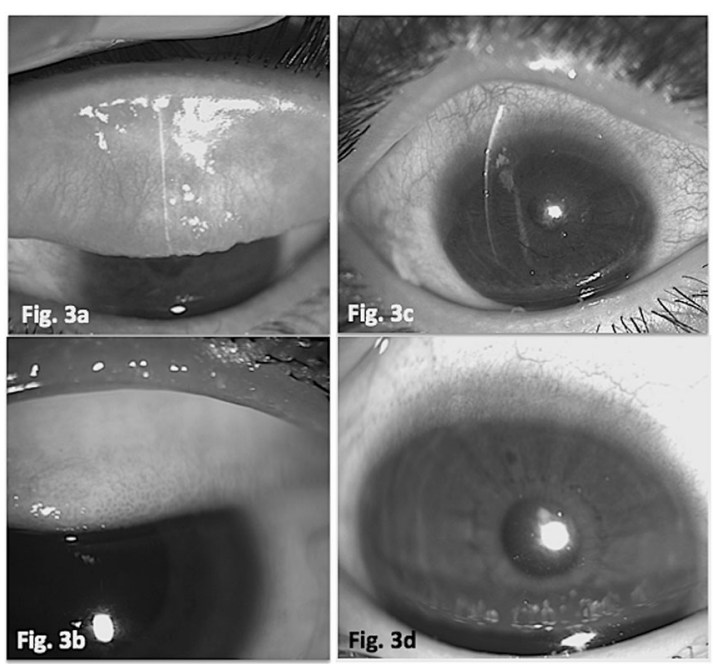

Fig. 3 Clinical photographs showing baseline and 3 months postcombined treatment effect. a Baseline clinical image showing diffuse papillae with congestion, b 3 months post treatment showing resolved congestion and papillae. c Baseline clinical image showing diffuse conjunctival hyperemia, d 3 months post treatment showing resolved hyperemia.

\section{Adverse reactions}

Mild irritation and burning sensation were observed in 3/11 patients with topical CsA alone and in 4/11 patients with combined therapy. However, the complaints were not that severe to discontinue any medications.

\section{Discussion}

Chronic or recurrent inflammation, and the use of steroid to control this, in VKC is often the culprit for visually disabling complications such as glaucoma or cataract [2]. Inflammation in VKC is mediated; predominantly by $\mathrm{IgE}$, Th2 lymphocytes, eosinophillic degranulation, and histamine-induced chemotaxis of fibroblasts. Commonly used topical medications acting on these pathways include antihistaminics, mast cell stabilizers (sodium cromoglycate, ketotifen, and lodoxamide), and dual acting agents such as olopatadine. These usually suffice in mild to moderate cases of VKC. However, cases having severe VKC often need 
treatment in the form of stronger anti-inflammatory agents such as topical corticosteroids. VKC is often associated with frequent recurrences, which might lead to steroid dependence, and complications like cataract and glaucoma. Management of such cases is challenging and often requires steroid-sparing agents.

In our series, all the cases had developed glaucoma following use of steroids. Although, use of CsA lead to improvement in symptoms within 2 weeks of therapy, it was not that significant. Also, the patients were not satisfied. Tacrolimus has been found to be successful in cases of severe and refractory VKC even those who are resistant to CsA [5, 6, 18-21, 25, 26]. Hence, we included it into our treatment regimen. Inclusion of tacrolimus leads to marked reduction in symptoms as well as signs.

Tzu et al. first reported the use of a combination of topical CsA and tacrolimus ointment. They evaluated the role of combination of topical CsA $0.05 \%$ and tacrolimus ointment $0.03 \%$ in a prospective case series involving ten patients with AKC [23]. They concluded that these immune modulators reduce the number of flare-ups and may eliminate the need of topical steroids. They included patients with AKC only and administered topical CsA for keratoconjunctivitis while tacrolimus ointment on lid skin for associated atopic dermatitis. CsA $0.05 \%$ was given 2-6 times daily for a minimum duration of 2 months following which tacrolimus ointment $0.03 \%$ BD was added for lid eczema. In current study we included cases with VKC and secondary glaucoma only. Our cases did not have any atopic skin disease. Besides, tacrolimus was initiated within 2 weeks of CsA.

The better response following inclusion of tacrolimus may be explained on the basis of higher potency of tacrolimus. Although both are calcineurin inhibitors, they differ in their chemical structure (CsA being a cyclic endecapeptide while tacrolimus is a macrocyclic lactone), mechanism of binding to calcineurin receptor and potency [22]. Tacrolimus has a higher potency, as it exhibits similar effects to CsA at concentrations 100 times lower. In addition, both these drugs lead to inhibition of calcineurin receptor by binding to different categories of immunophilins (CsA binds mainly to cyclophilin A, the predominant cyclophilin found within $\mathrm{T}$ cells, whereas tacrolimus binds to FK-binding proteins, in particular FKBP12) [22]. Although, the exact mechanism of this synergistic effect is difficult to explain pharmacologically, with current evidence, it is possible that either of the drugs might not be effective enough to block all the calcineurin receptors when prescribed alone. It may be possible that tacrolimus might also be acting through other pathways of inhibiting inflammation than calcineurin receptor blockade alone. Thus, combination therapy was observed to cause more complete immunosuppression than CsA alone.
We believe, in our cases CsA alone (at concentration $0.1 \%$ ) was insufficient to control the inflammation and inclusion of a drug with higher potency such as tacrolimus leads to a more effective control of inflammation. Previous studies have suggested that CsA alone is effective in acute cases of VKC and in our cases also we observed significant improvement within 2 weeks but the response was suboptimal considering patients morbidity [5-11, 16, 17]. This suboptimal response may be due to the severe nature of inflammation, in cases of VKC seen in our part of the world. Continuation of CsA might have led to complete resolution, however, inclusion of tacrolimus leads to a rapid relief of patients' morbidity. Thus, we believe tacrolimus should be included in cases of $\mathrm{VKC}$ where steroid is contraindicated and CsA does not lead to adequate control of inflammation.

A question may be raised that "if the rapid resolution was only due to tacrolimus or CsA itself or both?" It is well known, that a particular drug leads to improvement in symptoms rapidly in the immediate phase of administration. The rate of resolution usually decreases subsequently. In our series, tacrolimus led to resolution of symptoms at a rate, which was significantly higher than CsA itself. Also, if CsA would have been effective it should have caused rapid resolution of symptoms in the first 2 weeks itself; thus, the resolution of acute phase of the disease in 2 nd week of combined treatment at a rate higher than CsA use in the first 2 weeks of the disease, clearly suggests that tacrolimus is solely responsible for the rapidity at which clinical features improved.

Besides, another query could be regarding continuation of CsA even after inclusion of tacrolimus in the treatment regimen. While CsA has been FDA approved for use in ocular disorders like dry eye in United States of America and for VKC in few countries like Japan, topical tacrolimus is still an off-label drug [2, 27]. Besides, the long-term use of tacrolimus ointment has been reported to have side effects and the dose and frequency is also markedly variable [28, 29]. Thus, in our study, tacrolimus was included only for 3 months, while CsA was continued for long-term inflammation control and prevention of recurrences.

The major limitation of our study is that both the change in subjective and objective score at 2 weeks of CsA therapy and at 1 week of combined therapy were statistically significant due to which we could not prove statistically that combined therapy was better. This might be due to the small sample size but looking into the rarity of severe VKC cases with steroid-induced complications, this can be justified. Another issue with the study could be lack of a control group. So, a randomized study with comparison of two groups; one with only $\mathrm{CsA}$ and the other with combined treatment will be the best to prove superiority of the combine treatment. However, VKC with steroid-induced 
glaucoma is too rare an entity to allow for such a randomized study to be feasible.

Both tacrolimus and CsA have been proven to be effective, when used individually, in the management of allergic conjunctivitis but there is only one study suggesting that both can be used together with additive effect in AKC and lid eczema. In our study, we explored the synergistic effect of tacrolimus and CsA in steroid intolerant cases of VKC. Our study highlights that when CsA efficacy is suboptimal, addition of tacrolimus can improve the therapeutic response. To the best of our knowledge, this has never been explored in past. Although, tacrolimus use has increased among the corneal surgeons, it is still an off-label drug, including in our country. Thus, we prefer CsA to tacrolimus initially; as an alternative to steroids for longterm inflammation control and we include tacrolimus if CsA fails to achieve optimal response. To conclude combined use of CsA and tacrolimus may lead to rapid resolution of symptoms and reduced recurrence rate in cases with severe VKC where steroid has to be avoided.

\section{Summary}

\section{What was known before}

- CsA and tacrolimus are effective for the treatment of VKC.

\section{What this study adds}

- When CsA efficacy is suboptimal, addition of tacrolimus can improve the therapeutic response in cases of severe steroid intolerant VKC.

\section{Compliance with ethical standards}

Conflict of interest The authors declare that they have no conflict of interest.

Publisher's note Springer Nature remains neutral with regard to jurisdictional claims in published maps and institutional affiliations.

\section{References}

1. Kumar S. Vernal keratoconjunctivitis: a major review. Acta Ophthalmol. 2009;87:133-47.

2. Singhal D, Sahay P, Maharana PK, Raj N, Sharma N, Titiyal JS. Vernal keratoconjunctivitis. Surv Ophthalmol. 2019;64:289-311.

3. Ang M, Ti S-E, Loh R, Farzavandi S, Zhang R, Tan D, et al. Steroid-induced ocular hypertension in Asian children with severe vernal keratoconjunctivitis. Clin Opthalmol. 2012;6:1253-8.
4. Ang M, Ho C-L, Tan D, Chan C. Severe vernal keratoconjunctivitis requiring trabeculectomy with mitomycin $\mathrm{C}$ for corticosteroid-induced glaucoma. Clin Exp Ophthalmol. 2012;40: e149-155.

5. Al-Amri AM, Fiorentini SF, Albarry MA, Bamahfouz AY. Longterm use of $0.003 \%$ tacrolimus suspension for treatment of vernal keratoconjunctivitis. Oman J Ophthalmol. 2017;10:145-9.

6. Chatterjee S, Agrawal D. Tacrolimus in corticosteroid-refractory vernal keratoconjunctivitis. Cornea. 2016;35:1444-8.

7. Pucci N, Caputo R, Mori F, De Libero C, Di Grande L, Massai C, et al. Long-term safety and efficacy of topical cyclosporine in 156 children with vernal keratoconjunctivitis. Int $\mathrm{J}$ Immunopathol Pharmacol. 2010;23:865-71.

8. Pucci N, Caputo R, di Grande L, de Libero C, Mori F, Barni S, et al. Tacrolimus vs. cyclosporine eyedrops in severe cyclosporine-resistant vernal keratoconjunctivitis: a randomized, comparative, double-blind, crossover study. Pediatr Allergy Immunol Off Publ Eur Soc Pediatr Allergy Immunol. 2015;26:256-61.

9. Erdinest N, Ben-Eli H, Solomon A. Topical tacrolimus for allergic eye diseases. Curr Opin Allergy Clin Immunol. 2019;19: 535-43.

10. Kumari R, Saha BC, Sinha BP, Mohan N. Tacrolimus versus cyclosporine- comparative evaluation as first line drug in vernal keratoconjuctivitis. Nepal J Ophthalmol Biannu Peer-Rev Acad J Nepal Ophthalmic Soc NEPJOPH. 2017;9:128-35.

11. Vichyanond $P$, Kosrirukvongs $P$. Use of cyclosporine $A$ and tacrolimus in treatment of vernal keratoconjunctivitis. Curr Allergy Asthma Rep. 2013;13:308-14.

12. Leonardi A. Vernal keratoconjunctivitis: pathogenesis and treatment. Prog Retin Eye Res. 2002;21:319-39.

13. Vichyanond P, Tantimongkolsuk C, Dumrongkigchaiporn P, Jirapongsananuruk $\mathrm{O}$, Visitsunthorn $\mathrm{N}$, Kosrirukvongs $\mathrm{P}$. Vernal keratoconjunctivitis: result of a novel therapy with $0.1 \%$ topical ophthalmic FK-506 ointment. J Allergy Clin Immunol. 2004;113:355-8.

14. Shoughy SS, Jaroudi MO, Tabbara KF. Efficacy and safety of low-dose topical tacrolimus in vernal keratoconjunctivitis. Clin Ophthalmol. 2016;10:643-7.

15. Kheirkhah A, Zavareh MK, Farzbod F, Mahbod M, Behrouz MJ. Topical $0.005 \%$ tacrolimus eye drop for refractory vernal keratoconjunctivitis. Eye. 2011;25:872-80.

16. Çoban-Karataş M, Özkale Y, Altan-Yaycıoğlu R, Sızmaz S, Pelit A, Metindoğan S, et al. Efficacy of topical $0.05 \%$ cyclosporine treatment in children with severe vernal keratoconjunctivitis. Turk J Pediatr. 2014;56:410-7.

17. Keklikci U, Dursun B, Cingu AK. Topical cyclosporine a $0.05 \%$ eyedrops in the treatment of vernal keratoconjunctivitis-randomized placebo-controlled trial. Adv Clin Exp Med Organ Wroclaw Med Univ. 2014;23:455-61.

18. Pucci N, Novembre E, Lombardi E, Cianferoni A, Bernardini R, Massai $\mathrm{C}$, et al. Atopy and serum eosinophil cationic protein in 110 white children with vernal keratoconjunctivitis: differences between tarsal and limbal forms. Clin Exp Allergy J Br Soc Allergy Clin Immunol. 2003;33:325-30.

19. Shoji J, Ohashi Y, Fukushima A, Miyazaki D, Uchio E, Takamura E, et al. Topical tacrolimus for chronic allergic conjunctival disease with and without atopic dermatitis. Curr Eye Res. 2019;44:796-805.

20. Müller EG, Santos MSD, Freitas D, Gomes JÁP, Belfort R. Tacrolimus eye drops as monotherapy for vernal keratoconjunctivitis: a randomized controlled trial. Arq Bras Oftalmol. 2017;80:154-8.

21. Al-Amri AM. Long-term follow-up of tacrolimus ointment for treatment of atopic keratoconjunctivitis. Am J Ophthalmol. 2014;157:280-6. 
22. Barbarino JM, Staatz CE, Venkataramanan R, Klein TE, Altman RB. PharmGKB summary: cyclosporine and tacrolimus pathways. Pharmacogenet Genom. 2013;23:563-85.

23. Tzu JH, Utine CA, Stern ME, Akpek EK. Topical calcineurin inhibitors in the treatment of steroid-dependent atopic keratoconjunctivitis. Cornea. 2012;31:649-54.

24. Müller GG, José NK, de Castro RS. Topical tacrolimus $0.03 \%$ as sole therapy in vernal keratoconjunctivitis: a randomized doublemasked study. Eye Contact Lens. 2014;40:79-83.

25. Labcharoenwongs $\mathrm{P}$, Jirapongsananuruk $\mathrm{O}$, Visitsunthorn $\mathrm{N}$, Kosrirukvongs P, Saengin P, Vichyanond P. A double-masked comparison of $0.1 \%$ tacrolimus ointment and $2 \%$ cyclosporine eye drops in the treatment of vernal keratoconjunctivitis in children. Asian Pac J Allergy Immunol. 2012;30:177-84.

26. Liendo VL, Vola ME, Barreiro TP, Wakamatsu TH, Gomes JÁP, Santos MSD. Topical tacrolimus for the treatment of severe allergic keratoconjunctivitis in children. Arq Bras Oftalmol. 2017;80:211-4.

27. Takamura E, Uchio E, Ebihara N, Okamoto S, Kumagai N, Shoji $\mathrm{J}$, et al. [A prospective, observational, all-prescribed-patients study of cyclosporine $0.1 \%$ ophthalmic solution in the treatment of vernal keratoconjunctivitis]. Nippon Ganka Gakkai Zasshi. 2011;115:508-15.

28. Castellsague J, Kuiper JG, Pottegård A, Anveden Berglind I, Dedman $\mathrm{D}$, Gutierrez L, et al. A cohort study on the risk of lymphoma and skin cancer in users of topical tacrolimus, pimecrolimus, and corticosteroids (Joint European Longitudinal Lymphoma and Skin Cancer Evaluation_JOELLE study). Clin Epidemiol. 2018;10:299-310.

29. Legendre L, Barnetche T, Mazereeuw-Hautier J, Meyer N, Murrell D, Paul C. Risk of lymphoma in patients with atopic dermatitis and the role of topical treatment: a systematic review and meta-analysis. J Am Acad Dermatol. 2015;72:992-1002. 